\title{
Pulmonary hypertension after transjugular intrahepatic portosystemic shunt (TIPS)
}

\author{
R.M.J.L. van der Heijde*, J.S. Laméris**, B. van den Berg', \\ C.A. Wagenvoort ${ }^{++}$, C. Hilvering*, H.R. van Buuren\#
}

Pulmonary hypertension after transjugular intrahepatic portosystemic shunt (TIPS). R.M.J.L. van der Heijde, J.S. Laméris, B. van den Berg, C.A. Wagenvoort, C. Hilvering, H.R. van Buuren. (CERS Journals Ltd 1996.

ABSTRACT: We reported the case of a patient in whom severe, and ultimately fatal, pulmonary hypertension developed 1.5 yrs after transjugular intrahepatic portosystemic shunt (TIPS).

Pulmonary artery pressures were not affected by $100 \%$ oxygen, prostacyclin or nifedipine. Postmortem examinations showed pulmonary and vascular abnormalities typical of pulmonary hypertension.

Pulmonary artery pressures should be measured in each patient with otherwise not readily explained dyspnoea following transjugular intrahepatic portosystemic shunt.

Eur Respir J., 1996, 9, 1562-1564.
Depts of *Pulmonary Diseases, **Radiology, +Intensive Care and \#Hepatogastroenterology, University Hospital Rotterdam, Rotterdam, The Netherlands. ++Dept of Pathology, Erasmus University, Rotterdam, The Netherlands.

Correspondence: R.M.J.L. van der Heijde, Dept of Pulmonary Diseases, University Hospital Rotterdam, Dr. Molewaterplein 40, 3014 GD Rotterdam, The Netherlands

Keywords: Portal hypertension, pulmonary hypertension, transjugular intrahepatic portosystemic shunt

Received: August 181995

Accepted after revision December 41995
Transjugular intrahepatic portosystemic shunt (TIPS) has recently been introduced as treatment for consequences of portal hypertension, such as variceal haemorrhage and refractory ascites $[1,2]$. Several complications in placement of TIPS have been reported, including stent dislodgement, haemobilia, liver capsule rupture, intraabdominal bleeding, encephalopathy, haemolysis, cholestasis, renal failure and sepsis [1-3]. We describe a patient who developed pulmonary hypertension 1.5 yrs after TIPS insertion.

\section{Case report}

A 45 year old man with alcoholic liver cirrhosis was admitted to hospital due to bleeding from large gastric varices. After initial control of the bleeding with endoscopic sclerotherapy, a TIPS was inserted. After a year without medical problems, the patient was readmitted due to bleeding originating from a gastric varix. Recatheterization with phlebography revealed subtotal stent stenosis and a large coronary vein feeding gastric varices. A second stent was inserted inside the old one and embolization of the coronary vein was performed.

Six months later, the patient presented with exertional dyspnoea and syncope. His medication consisted of spironolactone, furosemide, lactulose and ranitidine. At physical examination, arterial and central venous pressures were normal. Heart rate was 84 beats $\cdot \mathrm{min}^{-1}$. No jaundice, ascites, oedema, cyanosis or finger-clubbing was found. Normal heart sounds and a short ejection murmur at the left sternal border were noted. The lungs were normal on examination. The liver was felt $5 \mathrm{~cm}$ below the right costal margin.
Laboratory investigation showed mild iron deficiency anaemia (haemoglobin $5.2 \mathrm{mmol} \cdot \mathrm{L}^{-1}$ ). Arterial blood gas analysis was normal. Ventilatory function was normal: total lung capacity (TLC) $7.89 \mathrm{~L}$, and forced expiratory volume in one second (FEV1) $3.67 \mathrm{~L}$ (95\% predicted). Transfer factor of the lungs for carbon monoxide was normal. Doppler ultrasound examination suggested normal TIPS function. In contrast to the chest radiographic examination obtained before the first TIPS, the heart was increased in size and lung vessels were prominent. The lung parenchyma showed no abnormalities. Cardiac ultrasound showed dilation of right atrium and right ventricle, with insufficiency of the tricuspid valve. The function and dimensions of the left ventricle were considered normal. Pulmonary ventilation and perfusion scans were normal. Continuous registration of oxygen saturation during the night revealed no periods of hypoxaemia.

The patient was treated with blood transfusion and the

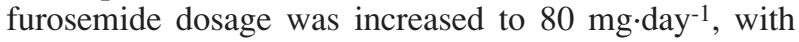
good clinical response.

For further haemodynamic analysis, a Swan-Ganz thermodilution catheter and a radial artery line were inserted. Baseline measurements were obtained whilst the patient was breathing room air. Several interventions were studied: $100 \%$ oxygen, infusion of prostacyclin at doses of 4 and $8 \mathrm{ng} \cdot \mathrm{kg}^{-1} \cdot \mathrm{min}$ and of nifedipine at $0.1,0.15$ and $0.2 \mathrm{mg} \cdot \mathrm{min}^{-1}$ (table 1 ). Measurements were obtained after $30 \mathrm{~min}$ stabilization. In between these interventions, baseline conditions were reassumed for $30 \mathrm{~min}$. These measurements showed fixed pulmonary hypertension, unaffected by any of the administered drugs or $100 \%$ oxygen. Pulmonary capillary wedge pressure was normal, as was arterial oxygen tension. Measurements at rest were repeated after treatment for 1 week with nifedipine, 60 
Table 1. - Effects of vasodilator drugs on the circulation

\begin{tabular}{lcccc}
\hline & Baseline & $\begin{array}{c}\text { Prostacyclin } \\
8 \mathrm{ng} \cdot \mathrm{kg}^{-1} \cdot \mathrm{min}\end{array}$ & $\begin{array}{c}\text { Nifedipine } \\
0.2 \mathrm{mg} \cdot \mathrm{min}^{-1}\end{array}$ & $\begin{array}{c}\text { After 1 week } \\
\text { nifedipine }\end{array}$ \\
\hline $\bar{P}_{\text {pa }} \mathrm{mmHg}$ & 38 & 39 & 45 & 50 \\
$P_{\text {cv }} \mathrm{mmHg}$ & 4 & 3 & 7 & 13 \\
$P_{\text {cwp }} \mathrm{mmHg}$ & 6 & 8 & 7 & 12 \\
$Q^{\prime}$ th L·min-1 & 8.2 & 10.6 & 9.3 & 9.8 \\
\hline
\end{tabular}

$\bar{P}_{\text {pa: }}$ mean pulmonary artery pressure; $P_{\text {cv }}$ : central venous pressure; $P_{\text {cwp: }}$ pulmonary capi-

llary wedge pressure; $Q^{\prime}$ th: cardiac output (thermodilution method).

$\mathrm{mg} \cdot \mathrm{day}^{-1}$, revealing no substantial effect of nifedipine. After exercise, an increase in pulmonary arterial pressure and a drop in mixed venous oxygen saturation were found, indicating a severely disturbed pulmonary circulation.

Phlebography of the TIPS shunt was repeated and revealed no thrombosis or other abnormalities. At this stage, liver transplantation was considered but rejected because the patient continued to consume alcohol. Gradual right-sided heart failure developed, initially responding to increasing doses of diuretics and angiotensin-converting enzyme (ACE) inhibitors. Eventually, the patient died from severe right heart failure, with massive oedema, tense ascites and sepsis.

At autopsy, micronodular cirrhosis of the liver (weight 2,300 g), splenomegaly (weight $1,000 \mathrm{~g}$ ) and ascites were found. The TIPS stent was in situ and patent despite a small fresh thrombus lining the inner wall. The lung tissue was oedematous. Microscopically, the pulmonary muscular arteries showed mild medial hypertrophy and mild intimal fibrosis, mostly of the concentric-laminar type (fig. 1a) but post-thrombotic lesions were rare. Fibrinoid necrosis was observed in several arterial branches and there were fairly numerous dilatation lesions and plexiform lesions (fig. 1b). Recent thrombi were very scarce.

a)

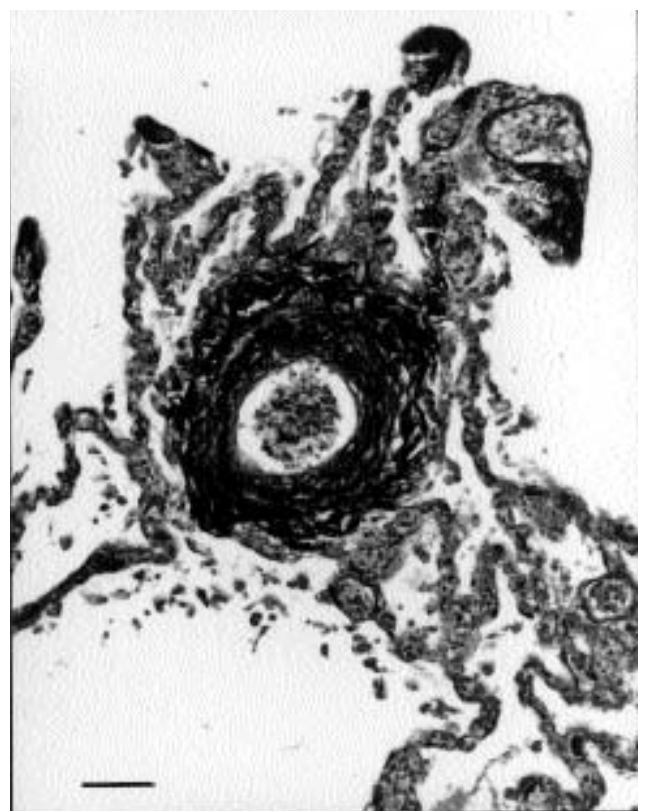

\section{Discussion}

This patient developed severe, and ultimately fatal, pulmonary hypertension 1.5 yrs following TIPS, a complication which has not been described previously. Clinical evidence of pre-existing pulmonary hypertension or other primary pulmonary or cardiac disease was absent. Pulmonary wedge pressure was notably normal 1.5 yrs after TIPS placement. However, since pulmonary artery pressures were not measured before TIPS, the possibility that TIPS caused a worsening of pre-existing pulmonary hypertension cannot be excluded. If an increase in venous return had caused pulmonary hypertension, we would have expected symptoms to occur shortly after TIPS placement, whereas our patient became symptomatic after 1.5 yrs. A rise in cardiac output, even with a pre-existing slightly elevated mean pulmonary artery pressure $\left(\bar{P}_{\mathrm{pa}}\right)$, will not have led to such high values in $P$ pa, as seen in our patient. Also, considering the characteristic histological features of pulmonary hypertension, we assume that an increased venous return was not of major aetiological importance.

In patients with liver disease and portal hypertension, a number of pulmonary complications have been described. The most common pulmonary complication is the hepatopulmonary syndrome, caused by intrapulmonary vascular

b)

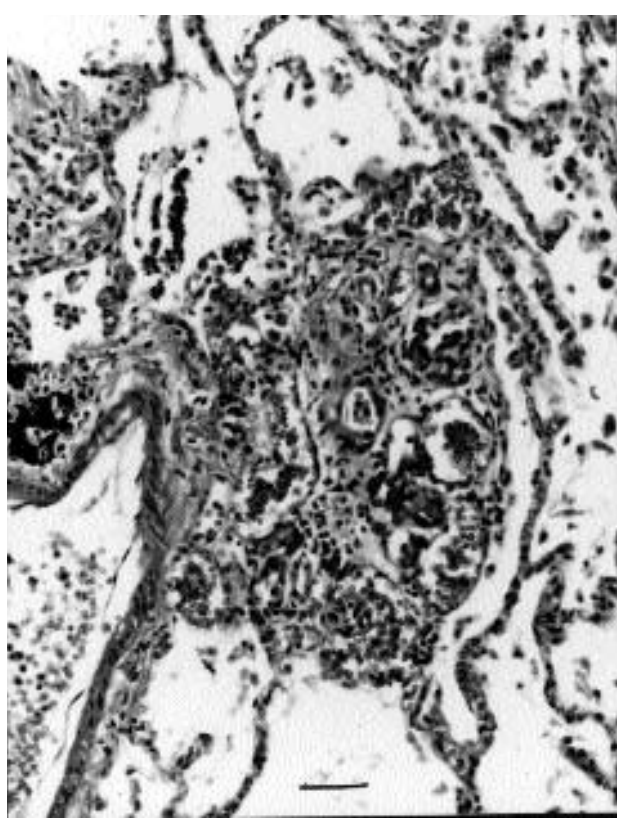

Fig. 1. - a) Muscular pulmonary artery with narrowing by concentric-laminar intimal fibrosis. (Elastic van Gieson's stain; original magnification $\times 180$ : scale bar $=50 \mu \mathrm{m})$. b) Plexiform lesion in a branch immediately after its origin from a parent muscular pulmonary artery (Haematoxylin and eosin stain; original magnification $\times 180$ : scale bar $=50 \mu \mathrm{m})$. 
dilatation with a resulting right-to-left intrapulmonary shunt [4]. Pulmonary hypertension is much less frequent. MCDONNELl et al. [5] found a prevalence of pulmonary hypertension at autopsy of $0.73 \%$. Another study reported elevated pulmonary artery pressures in $2 \%$ of patients with portal hypertension at the time of transvenous liver biopsy [6]. Pulmonary hypertension has also been reported in patients with extrahepatic portal hypertension. In patients with surgical portosystemic shunts, a relatively high incidence has been suggested [6-9]. The most widelyaccepted hypothesis for pulmonary hypertension associated with portal hypertension is the shunting of vasoactive substances, originating from the splanchnic vessels (and usually inactivated in the liver) into the pulmonary vasculature, resulting in vasoconstriction and chronic arterial changes. The same pathogenesis may have been present in our patient.

Plexogenic pulmonary hypertension is initially characterized by an increased arterial muscularity, followed by cellular intimal proliferation and characteristic concentriclaminar intimal fibrosis [10]. In the final stages of the disease, fibrinoid necrosis and pathognomonic plexiform lesions are found [10]. These abnormalities were all found in our patient, with a marked abundancy of plexiform lesions.

The therapeutic options in patients with pulmonary hypertension are limited. In our patient, medical therapy, including vasodilators and oxygen, failed to ameliorate haemodynamics. Although a beneficial effect of liver transplantation has been reported [11], more data are needed to define the place of this therapeutic option in patients suffering from end-stage liver disease accompanied by pulmonary hypertension.

The morbidity and mortality associated with TIPS has been reported to be relatively low, especially when compared to surgical portosystemic shunts. Given the previously reported higher incidence of pulmonary hypertension after surgical shunting, and the increasing popularity of TIPS, it can be expected that more cases will be noted in the near future. Unaltered pulmonary artery pressures were found 1 months after TIPS [12], but studies with a more prolonged follow-up have not been reported. Consideration should be given to measurement of pulmonary artery pressures in each patient prior to TIPS, and at each recatheterization performed either routinely after 3-6 months or when TIPS function seems compromised, to establish pulmonary hypertension at an early stage. Undoubtedly, such measurements will lengthen the procedure, albeit probably only to a minor degree. Currently, it can be recommended that pulmonary embo- lism is excluded, either by radiolabelled lung scanning or angiography, and that pulmonary artery pressures are measured in patients with otherwise not readily explained dyspnoea following TIPS.

\section{References}

1. Rössle M, Haag K, Ochs A, et al. The transjugular intrahepatic portosystemic shunt procedure for variceal bleeding. N Engl J Med 1994; 330: 165-171.

2. LaBerge JM, Ring EJ, Gordon RL, et al. Creation of transjugular intrahepatic portosystemic shunts with the wallstent endoprosthesis: results in 100 patients. Radiology 1993; 187: 413-420.

3. Cheng KM, Lameris JS, de Man RA, Pieterman H, van Buuren HR. Haemolysis and cholestasis following implantation of a transjugular intrahepatic portosystemic shunt. Eur J Gastroent Hep 1994; 6: 749-751.

4. Rodriguez-Roisin R, Krowka MJ. Is severe arterial hypoxaemia due to hepatic disease an indication for liver transplantation? A new therapeutic approach. Eur Respir $J$ 1994; 7: 839-842.

5. McDonnell PJ, Toye P, Hutchins GM. Primary pulmonary hypertension and cirrhosis. Are they related? Am Rev Respir Dis 1983; 127: 437-441.

6. Hadengue A, Benhayoun MK, Lebrec D, Benhamou JP. Pulmonary hypertension complicating portal hypertension: prevalence and relation to splanchnic hemodynamics. Gastroenterology 1991; 100: 520-528.

7. Senior RM, Britton RC, Turino GM, et al. Pulmonary hypertension associated with cirrhosis of the liver and with portocaval shunts. Circulation 1968; 37: 88-96.

8. Robalino BD, Moodie DS. Association between primary pulmonary hypertension and portal hypertension: analysis of its pathophysiology and clinical, laboratory and hemodynamic manifestations. J Am Coll Cardiol 1991; 17: 492-498.

9. Lebrec D, Capron JP, Dhumeaux D, Benhamou JP. Pulmonary hypertension complicating portal hypertension. Am Rev Respir Dis 1979; 120: 849-856.

10. Edwards BS, Weir EK, Edwards WD, et al. Coexistent pulmonary and portal hypertension: morphologic and clinical features. J Am Coll Cardiol 1987; 10: 1233-1238.

11. Scott V, DeWolf A, Kang Y, Martin M, et al. Reversibility of pulmonary hypertension after liver transplantation. Transplant Proc 1993; 25: 1789-1790.

12. Azoulay D, Castaing D, Dennison A, Martino W, Eyraud $\mathrm{D}$, Bismuth $\mathrm{H}$. Transjugular intrahepatic portosystemic shunt worsens the hyperdynamic circulatory state of the cirrhotic patient: preliminary report of a prospective study. Hepatology 1994; 19: 129-132. 